GRASAS Y ACEITES 68 (3)

July-September 2017, e208

ISSN-L: 0017-3495

doi: http://dx.doi.org/10.3989/gya.0225171

\title{
Comparison between different liquid-liquid and solid phase methods of extraction prior to the identification of the phenolic fraction present in olive oil washing wastewater from the two-phase olive oil extraction system
}

\author{
S. Jiménez-Herrera ${ }^{\mathrm{a}, \bowtie}$, J.M. Ochando-Pulido ${ }^{\mathrm{a}}$ and A. Martínez-Ferez ${ }^{\mathrm{a}}$ \\ ${ }^{a}$ Department of Chemical Engineering, University of Granada, Campus Fuentenueva, 18071 Granada, Spain. \\ ${ }^{\otimes}$ Corresponding author: silvia-jh@hotmail.com
}

Submitted: 23 February 2017; Accepted: 24 April 2017

\begin{abstract}
SUMMARY: Phenolic compounds from olive mill wastewater (OMW), are characterized by a strong antioxidant activity. At the same time, they represent an environmental problem because they are difficult to degrade. The purpose of this work was to identify these biologically active compounds in the OMW from two-phase olive oil production in order to convert a polluting residue into a source of natural antioxidants. After optimizing the extraction process of phenolic compounds using liquid-liquid extraction (LLE) and solid phase extraction (SPE) methods, it was determined that the most appropriate sequence comprised a previous centrifugation to remove the lipid fraction, followed by liquid extraction with ethyl acetate or SPE. The most important compounds identified in olive oil washing wastewater (OOWW) were tyrosol, hydroxytyrosol and succinic acid; whereas the ones in the wastewater derived from the washing of the olives (OWW) were cresol, catechol, 4-methylcatechol, hydrocinnamic acid and p-hydroxy-hydrocinnamic acid.
\end{abstract}

KEYWORDS: Antioxidants; Ethyl acetate; Extraction; Hydroxytyrosol; Olive oil wastewater; Polyphenols

RESUMEN: Comparación entre métodos de extracción líquido-líquido y en fase sólida previos a la identificación de la fracción fenólica presente en las aguas residuales procedentes del lavado del aceite de oliva obtenido mediante el sistema de extracción de aceite de oliva en dos fases. Los compuestos fenólicos presentes en las aguas residuales de la industria oleícola (OMW) se caracterizan por una gran actividad antioxidante. Por otra parte, suponen un problema medioambiental debido a que son difíciles de degradar. El objetivo de este trabajo fue la identificación de estos compuestos biológicamente activos que se encuentran en las OMW generadas del proceso de obtención del aceite de oliva por el sistema de dos fases, para así convertir un residuo contaminante en una fuente de antioxidantes naturales. Tras optimizar el proceso de extracción de los compuestos fenólicos utilizando extracción líquido-líquido (LLE) y extracción en fase sólida (SPE), se obtuvo que la secuencia más apropiada comprendió una centrifugación previa para eliminar la fracción lipídica, seguida de una extracción líquida con acetato de etilo o una SPE. Los compuestos más importantes identificados en las aguas residuales del lavado del aceite de oliva (OOWW) fueron tirosol, hidroxitirosol y el ácido succínico, mientras que los de las aguas residuales derivadas del lavado de las aceitunas (OWW) fueron cresol, catecol, 4-metilcatecol, ácido hidrocinámico y ácido p-hidroxi-hidrocinámico.

PALABRAS CLAVE: Acetato de etilo; Aguas residuales del aceite de oliva; Antioxidantes; Extracción; Hidroxitirosol; Polifenoles

ORCID ID: Jiménez-Herrera S http://orcid.org/0000-0003-0999-9407, Ochando-Pulido JM http://orcid.org/00000001-5564-7619, Martínez-Ferez A http://orcid.org/0000-0001-5750-7900

Citation/Cómo citar este artículo: Jiménez-Herrera S, Ochando-Pulido JM, Martínez-Ferez A. 2017. Comparison between different liquid-liquid and solid phase methods of extraction prior to the identification of the phenolic fraction present in olive oil washing wastewater from the two-phase olive oil extraction system. Grasas Aceites 68 (3), e208. http://dx.doi.org/10.3989/gya.0225171

Copyright: (C2017 CSIC. This is an open-access article distributed under the terms of the Creative Commons Attribution (CC-by) Spain 3.0 License. 


\section{INTRODUCTION}

Olive mill wastewater (OMW) generated in two-phase olive oil production consists of wastewater derived from the washing of the olives (OWW) and wastewater that leaves the vertical centrifuge machines (OOWW). Figure 1 shows the flow diagram of the continuous production process of olive oil by the two-phase extraction system, resulting in the generation of these effluents. The OOWW generated in the two-phase olive oil production process is the major waste product of this industry and one of the most serious environmental problems in Mediterranean countries. Spain, Italy, Portugal, Greece and the North African countries Syria, Algeria, Turkey, Morocco, Tunisia, Libya, and Lebanon are the largest producers in the world. Other countries such as France, Serbia and Montenegro, Macedonia, Cyprus, Egypt, Israel, and Jordan also produce a considerable annual amount of olive oil according to the data registered by International Olive Oil Council (IOOC, 2016). What is more, the production of olive oil is growing in countries such as China, USA, Australia and the Middle East. The current growth of the olive oil production sector is parallel to the development and modernization of olive oil factories, due to the greater global demand of olive oil.

OOWW is a heavily contaminated liquid stream that has an acidic $\mathrm{pH}$, black color, very high chemical oxygen demand (COD) and a high concentration

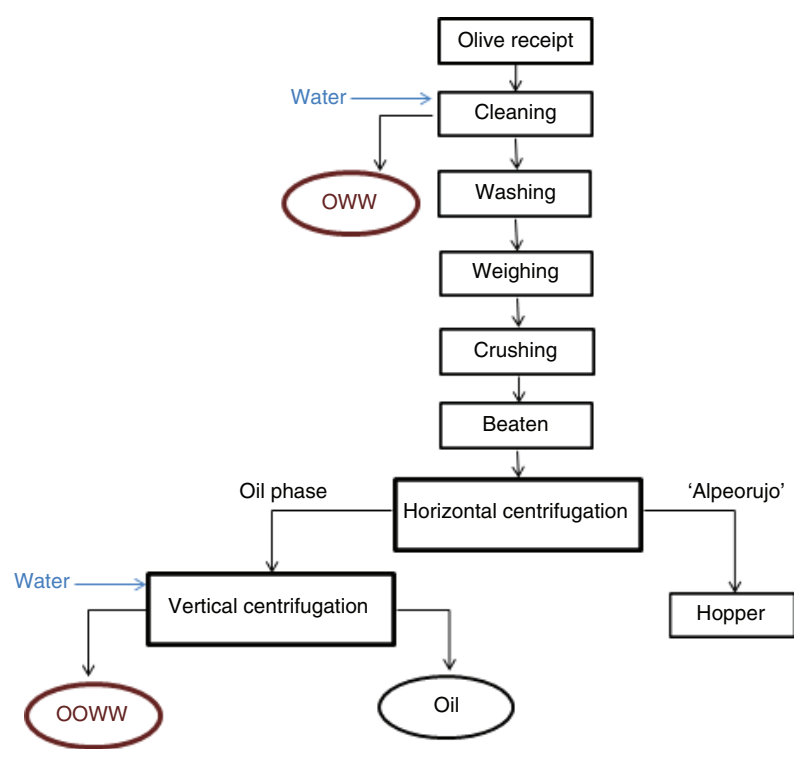

Figure 1. Flow diagram of the continuous production process of olive oil by the two-phase extraction system, resulting in the generation of effluents: olive oil washing wastewater (OOWW) and wastewater derived from the washing of the olives (OWW). of microbial growth-inhibiting components, such as tannins and phenols (Elkacmi et al., 2016). Because of its concentration of phenolic compounds, OOWW is highly polluting and phytotoxic, which impedes its biological degradation and produces harmful effects on the flora and fauna of disposed areas (Schieber et al., 2011).

On the other hand, the phenolic compounds from OOWW have a high antioxidant activity (Obied et al., 2005). The extraction of these biologically active compounds could convert this polluting and toxic waste into a source of antioxidants of great value for the pharmaceutical and food industries, in the prevention of different human diseases as well as for the inhibition of food oxidation (De Marco et al., 2007).

Phenolic compounds are composed of aromatic benzene ring/s, hydroxyl group/s and functional side chain/s. The most abundant and interesting phenolic compounds present in OOWW from the two-phase olive oil system are hydroxytyrosol and tyrosol (Takaç and Karakaya, 2009). One of the explanations for the formation of hydroxytyrosol is the hydrolysis of oleuropein (the main biophenol in many olive varieties) due to the action of esterases and acid hydrolysis of secoiridoid derivatives caused by the addition of $\mathrm{HCl}$ to the OOWW during oil extraction.

Hydroxytyrosol is one of the strongest antioxidants and it is, in part, responsible for the bitter taste of extra virgin olive oil. Research shows its antioxidant and beneficial properties for health as well as its good bioavailability (Torrecilla, 2010). Hydroxytyrosol has amphiphilic character which enables its uptake in the intestines and protects both lipid and aqueous cellular compartments. The strong antioxidant efficacy of hidroxytyrosol, due to the presence of the o-dihydroxyphenyl moiety, is a result of its high capacity for free radical scavenging during oxidation processes and to its reducing power on $\mathrm{Fe}^{3+}$ (Torres de Pinedo, 2005).

Hydroxytyrosol has the capacity to scavenge peroxyl radicals, which inhibits the oxidation of low-density lipoproteins (LDL), and carries cholesterol (LDL-C), a fundamental stage in the emergence of atherosclerosis and other cardiovascular diseases (Vázquez-Velasco et al. 2011). Moreover, this compound may produce a proapoptotic effect intervening in the expression of genes related to the tumor cell propagation of promyelocytes (HL60 cells) (Fabiani et al. 2011), as well as the inhibition of the development of some carcinogenic human cells (Bouallagui et al., 2011; Bulotta et al., 2011).

The antimicrobial properties of oleuropein, tyrosol and hydroxytyrosol have been tested in vitro against viruses, bacteria and protozoa (Bisignano et al., 1999). 
The relation of hydroxytyrosol to platelet function has been investigated and it was observed that it impedes the chemically induced aggregation, the accumulation of the thromboxane pro-aggregant agent in human serum, the production of the proinflammatory leukotriene molecules and the activity of arachidonate lipoxygenase (Visioli et al., 2002).

Hydroxytyrosol and its derivatives also have applications as microbicides to avoid HIV-infection, and other sexually transmitted diseases generated by fungi, bacteria or viruses (Gómez-Acebo et al., 2011).

Although the antioxidant capacity of tyrosol is much lower than that of hydroxytyrosol, tyrosol is an important antioxidant, and it is extracted rapidly from the intestinal tract. In addition, it can pass the blood brain barrier in large quantities. Researchers found tyrosol in the cerebrospinal fluid of rats that had taken tyrosol orally. Because it increases the total antioxidant levels of the brain, it can be used to treat disorders like Alzheimer's and Parkinson's diseases and can also be used to treat stroke and loss of memory (Geelings et al., 2003). Catechol and its derivatives are also phenolic antioxidants found in olive oil that have a great interest in the pharmaceutical and food industries.

In this framework, there are some studies which were aimed at the removal of the phenolic concentration present in two-phase OMW, e.g. by the Fenton process (Cañizares et al. 2009; Hodaifa et al., 2013), or found in other types of wastewater (Jiménez et al., 2017), with the aim to reuse the regenerated water.

On the other hand, for the recovery of these valuable phenolic compounds on an industrial scale, La Scalia et al. (2017) tested membrane filtration and reverse osmosis processes, whereas Zagklis et al. (2015) used filtration though membranes followed by resin adsorption/desorption, and vacuum distillation for the final concentration of phenols. Zafra et al. (2006) only used a liquid-liquid micro-extraction with ethyl acetate, and Elkacmi et al. (2017), after OMW delipidation with hexane, also extracted the phenolic compounds with ethyl acetate.

For the quantification of phenolic compounds, there are spectrophotometric methods such as the 4-aminoantipyrine method or the Folin-Ciocalteu method, which are generally used to quantify total phenol concentrations. These methods are easy but they are not precise, and it is not possible to quantify them individually because they simply evaluate the total phenolic concentration (Brune et al., 1991).

The aim of this study was the identification of the phenolic compounds present in the OMW from the two-phase olive oil extraction system. Specifically, OOWW and OWW generated in this system have been studied for the possible use of these liquid residues before conventional treatments as a source of natural antioxidants of interest in the pharmaceutical and food industries. For this goal, the optimization of different extraction methods was carried out, since in complex matrices, such as these OMW, the key to the determination is the preliminary sample processing, which requires a previous separation of the phenolic fraction from the other constituents present in the samples.

In this work, a comparison between liquidliquid extraction (LLE) and solid phase extraction (SPE) methods was made. Furthermore, the effect of a previous centrifugation step or hexane extraction in the efficiency was studied, and other components present in these wastewaters were identified. After the application of these extraction methods for phenol identification in OOWW, the best method obtained was also used to identify the main interesting compounds in OWW.

A particularity in this study has been the utilization of OMW generated by the two-phase olive oil system, which is a more recent process which involves a reduction in wastewater volume but an increased concentration in organic matter in comparison with the OMW obtained in the three-phase process (Borja et al. 2006) whose samples have been used in other works (Allouche et al., 2004; De Marco et al., 2007; Zagklis et al., 2015). Moreover, OOWW from vertical centrifuge machines generated by the two-phase olive oil extraction system and wastewater derived from the washing of the olives were used in this work, in comparison with other studies where phenolic compounds have been identified in OMW in general, consisting of a mixture of washing oil wastewater, olive washing wastewater and other residues generated in the oil industry. In contrast with other works, DeMarco et al. (2007) use OMW generated from the three-phase olive oil production process; other differences are that they do not specify the type of OMW; before the liquid-liquid extraction with ethyl acetate, the pre-treatment of the sample is different from this work, where whether a previous centrifugation is more appropriate, an extraction with hexane or both were studied. The compounds extracted in hexane were also identified in this work. In addition, for the identification of the compounds, these authors use HPLC. As in the case of DeMarco and colleagues, Allouche et $a l$. (2004) use wastewater generated from the threephase olive oil process, they do not specify the origin and only liquid-liquid extraction is performed. Another example is Deeb et al. (2012) who do not make a comparison between different extraction methods. 
TABLE 1. Initial characteristics of a) olive oil washing wastewater (OOWW) and b) wastewater derived from the washing of the olives (OWW)

\begin{tabular}{lcc}
\hline & a) OOWW & b) $\mathbf{O W W}$ \\
\cline { 2 - 3 } Parameters & Average value $\pm \mathbf{S D}^{\mathbf{a}}$ & ${\text { Average value } \mathbf{\pm} \mathbf{S D}^{\mathbf{b}}}^{\mathbf{b}}$ \\
\hline COD, $\mathrm{mg} \cdot \mathrm{L}^{-1}$ & $14928.00 \pm 53.00$ & $2514.20 \pm 53.00$ \\
Total phenols, $\mathrm{mg} \cdot \mathrm{L}^{-1}$ & $123.20 \pm 1.00$ & $14.76 \pm 1.00$ \\
Total solids, $\%$ & $0.5 \pm 0.15$ & $0.30 \pm 0.15$ \\
$\mathrm{pH}$ & $4.75 \pm 0.20$ & $5.80 \pm 0.20$ \\
\hline
\end{tabular}

${ }^{\mathrm{a}, \mathrm{b}}$ Values calculated for 3 replicates

\section{MATERIALS AND METHODS}

\subsection{Characteristics of wastewaters}

OOWW samples generated from the two-phase olive oil production process were collected from an olive oil production plant in Jaén (Spain), the main producer worldwide, and stored in $5 \mathrm{~L}$ low density polypropylene airtight containers at $-20^{\circ} \mathrm{C}$ until use.

Once the extraction methods were optimized, the best method was also used to perform the extraction of phenols but this time in OWW, also generated from the two-phase olive oil extraction in the same plant of Jaén (Spain).

Tables 1 (a) and (b) report the measured values of chemical oxygen demand (COD), total phenol concentrations, total solid weight percentages and $\mathrm{pH}$ of the raw OOWW and OWW used in this work, respectively.

\subsection{Reagents and equipment}

For this study, hexane (> 95\% purity) (Sigma Aldrich) and ethyl acetate (99.8\% purity) (Sigma Aldrich) were used as solvents, whereas BSTFA (N,Obis (trimethylsilyl) trifluoroacetamide) and pyridine (> 99\% purity) were utilized (Sigma Aldrich) for the silylation. For the solid phase extractions ISOLUTE ENV+ SPE Columns (Biotage) were used.

The centrifuge used in the experiments was a CL10 model (Thermo Scientific).

\subsection{Analytical methods}

To determine the chemical oxygen demand (COD) of these samples potassium dichromate was used in excess, in a hot sulphuric acid medium, and in the presence of silver sulphate, acting as catalyst, as well as mercury sulphate to eliminate the interference of chloride ions (Bullock et al. 1996).

To determine the total phenol concentration, Spectroquant Phenol Test 1.00856 (Merck, Germany) was used. It is a photometric method in which phenols and their ortho- and meta-substituted compounds react with 4-aminoantipyrine in buffered a solution in the presence of an oxidizing agent to form a red compound that can be determined photometrically. The method is analogous to EPA 420.1, APHA $5530 \mathrm{C}+\mathrm{D}$, ISO 6439, and ASTM D1783-01.

The analyses of polyphenols were performed using a high resolution gas chromatograph $(7890 \mathrm{~A}$ model, Agilent, USA) connected to a mass spectrometer of triple quadrupole (Quattro microGC, Waters, USA).

The set of GC conditions were the following ones:

- Capillary column of non-polar phase ZB-5MS (5\% phenyl and $95 \%$ dimethylpolysiloxane), $30 \mathrm{~m} \times 0.25 \mathrm{~mm} \times 0.25 \mu \mathrm{m}$; Injector in split mode (200:1); temperature program of $60^{\circ} \mathrm{C}(1 \mathrm{~min})$ up to $300^{\circ} \mathrm{C}(5 \mathrm{~min})$ at $10^{\circ} \mathrm{C} \cdot \mathrm{min}^{-1}$.

- MS Conditions: 45 Da to $450 \mathrm{Da}$ Fullscan; the conditions for electron impact ionization (EI) were an ion energy of $70 \mathrm{eV}$.

- $\quad$ The carrier gas used was helium (purity 99.999\%) at a flow rate of $1 \mathrm{~mL} \mathrm{~min}^{-1}$ and the sample volume in the direct injection mode was $1 \mu \mathrm{L}$.

The derivatization of phenolic compounds to make the sample volatile, improve its detectability and increase stability for the GC-MS analysis, was carried out following the procedure described by Zafra et al. (2006), in which a mixture of 20: 5: $25(\mathrm{v} / \mathrm{v} / \mathrm{v})$ BSTFA-pyridine-ethyl acetate (containing phenolic sample) is allowed to stand for 2 minutes at room temperature. The procedure is sufficient to provide an adequate derivatization.

\subsection{Pre-treatment of the sample}

Before the extraction procedure, a pre-treatment of the sample was carried out: $20 \mathrm{~mL}$ of OOWW were sonicated for $5 \mathrm{~min}$ and acidified to $\mathrm{pH}$ equal to 2 with $\mathrm{HCl}$ to permit the precipitation of proteins and the liberation of biophenols adhered to the cell wall components, since traces of crushed olives and oil can be found in these wastewaters, and to increase the solubility of phenolic components in the organic solvents (Obied et al. 2005). The acidification of OOWW was carried out because there are studies that demonstrate that the maximum phenol content is achieved at pH 2 (Lafkaa et al. 2011; Zafra et al. 2006). 


\subsection{Extraction}

After the pre-treatment (sonication and acidification) of six OOWW $20 \mathrm{~mL}$ samples (and their respective replicates in which more than 95\% reproducibility was obtained), the following different methods of extraction were studied:

1. Centrifugation+ Liquid-liquid extraction (LLE) with Hexane and Ethyl acetate.

2. Centrifugation+ Liquid-liquid extraction (LLE) with Ethyl acetate.

3. Liquid-liquid extraction (LLE) with Hexane and Ethyl acetate.

4. Liquid-liquid extraction (LLE) with Ethyl acetate.

5. Centrifugation+ Solid phase extraction (SPE).

6. Solid phase extraction (SPE).

\subsubsection{Centrifugation + LLE with Hexane and Ethyl acetate}

After the pre-treatment, the sample was centrifuged for $8 \mathrm{~min}$ at $4500 \mathrm{rpm}(\mathrm{G}$ force $=3118)$ and then washed with hexane in order to remove the lipid fraction: $20 \mathrm{~mL}$ of sample were mixed with $10 \mathrm{~mL}$ of hexane using a separating funnel and the mixture was vigorously shaken for 5 seconds. The phases were separated in $5 \mathrm{~min}$ and the washing was successively repeated twice. The two fractions of hexane collected were stored in an Erlenmeyer flask.

The extraction of phenolic compounds of the aqueous fraction was then carried out with ethyl acetate: the aqueous fraction was mixed with $20 \mathrm{~mL}$ of ethyl acetate and the mixture was vigorously shaken. The phases were separated and the extraction was successively repeated twice. The fractions of ethyl acetate collected were stored in another Erlenmeyer flask.

After this, anhydrous sodium sulphate was added to the two flasks to remove the residual water; then, each sample was filtered through paper filter, and the solvents were evaporated under vacuum.

\subsubsection{Centrifugation + LLE with Ethyl acetate}

After the pre-treatment, the sample was centrifuged for $8 \mathrm{~min}$ at $4500 \mathrm{rpm}$. Then $20 \mathrm{~mL}$ of the sample were mixed with $20 \mathrm{~mL}$ of ethyl acetate using a separating funnel and the mixture was vigorously shaken. The phases were separated and the extraction was successively repeated twice. The fractions of ethyl acetate collected were stored in an Erlenmeyer flask. Finally, anhydrous sodium sulphate was added, the sample was filtered and the solvent was evaporated under vacuum.

\subsubsection{LLE with Hexane and Ethyl acetate}

In this case, after the pre-treatment, no centrifugation was performed and the sample was washed with hexane: $20 \mathrm{~mL}$ of sample were mixed with $10 \mathrm{~mL}$ of hexane using a separating funnel. The mixture was vigorously shaken, the phases were then separated and washing was successively repeated twice.

The two fractions of hexane collected were stored in an Erlenmeyer flask.

The extraction of phenolic compounds of the aqueous fraction was thereafter performed using ethyl acetate: the aqueous fraction was mixed with $20 \mathrm{~mL}$ of ethyl acetate and the mixture was vigorously shaken. The phases were separated and the extraction was successively repeated twice. The fractions of ethyl acetate collected were stored in another Erlenmeyer flask.

Anhydrous sodium sulphate was added to the two flasks to remove the residual water. Finally, each sample was filtered through paper filter and evaporated under vacuum to remove the solvents.

\subsubsection{LLE with Ethyl acetate}

After the pre-treatment, no centrifugation was performed and the sample was just extracted with ethyl acetate: $20 \mathrm{~mL}$ of sample were mixed with 20 $\mathrm{mL}$ of ethyl acetate using a separating funnel; thereafter the mixture was vigorously shaken. The phases were separated and the extraction was successively repeated twice. The fractions of ethyl acetate were taken and stored in an Erlenmeyer flask, and anhydrous sodium sulphate was added; the sample was filtered and evaporated under vacuum, as formerly described.

It is important to highlight that this method required more time to separate the aqueous phase from the ethyl acetate fraction in the first extraction.

\subsubsection{Centrifugation $+S P E$}

After the pre-treatment, the sample was centrifuged for $8 \mathrm{~min}$ at $4500 \mathrm{rpm}(\mathrm{G}$ force $=3118)$. Subsequently, solid phase extraction was carried out using different types of cartridges than those used by other authors (De Marco et al. 2007; Visioli et al. 1999).

The SPE method consisted of a non-polar retention mechanism by ISOLUTE ENV+ SPE columns. This column is a hyper cross-linked hydroxylated polystyrene-divinylbenzene copolymer, with very high surface area, and a good option for extracting polar analytes. The very accessible surface of the sorbent allows the retention of the analytes.

The sorbent can impede hydrophobic interactions, such as methanol, which will compete for interaction with the surface, and elute the analyte.

For the extraction of phenols from the acidified OOWW sample using these columns before the analysis by GC, the column was washed with $3 \mathrm{~mL}$ of methanol. The column was rinsed with deionized water adjusted to $\mathrm{pH} 2$ with $\mathrm{HCl}$. A flow rate of up to $60 \mathrm{~mL} \cdot \mathrm{min}^{-1}$ was applied. Interferences 
were eluted with $10 \mathrm{~mL}$ of deionized water. The column was dried thoroughly by vacuum aspiration for $10 \mathrm{~min}$. The analytes were eluted twice with $1.5 \mathrm{~mL}$ of 5:95 (v/v) acetic acid/ ethyl acetate. The first aliquot to the column was applied, and it was soaked for $1 \mathrm{~min}$. Then the second aliquot was applied and the fractions were combined. Anhydrous sodium sulphate was added to remove the residual water; finally, the sample was filtered through paper filter and evaporated under vacuum.

\subsection{6. $S P E$}

After the pre-treatment of sonication and acidification and without centrifugation, the sample was extracted using an ISOLUTE ENV+ column just as the procedure previously explained.

\subsection{Recovery of polyphenols}

After evaporating the solvents contained in the eight Erlenmeyer flasks: 1) Ethyl acetate, 1) Hexane, 2) Ethyl acetate, 3) Ethyl acetate, 3) Hexane, 4) Ethyl acetate, 5) Ethyl acetate, 6) Ethyl acetate, the polyphenols that were adhered to the walls of these flasks were dragged by washing them twice with 1 $\mathrm{mL}$ of hexane, or with $1 \mathrm{~mL}$ of ethyl acetate the ones extracted with ethyl acetate. The samples were transferred to eight micro-vials and were dried to evaporate the solvents. Finally, for the silylation, 300 $\mu \mathrm{L}$ of BSTFA and $150 \mu \mathrm{L}$ of pyridine were added to each sample and the mixture was mechanically shaken for $2 \mathrm{~min}$ at room temperature. At this point the samples were ready to be injected into the gas chromatograph-mass spectrometer.

\section{RESULTS AND DISCUSSION}

Figure 2a shows the peaks corresponding to the compounds found in the ethyl acetate extract after the centrifugation of OOWW using the method comprising centrifugation + LLE with hexane and ethyl acetate, and the retention times of these peaks. The identified compounds were 2-hydroxypropanoic acid at $6.13 \mathrm{~min}$, succinic acid at $9.90 \mathrm{~min}$, tyrosol at $13.22 \mathrm{~min}$, hydroxytyrosol at $15.40 \mathrm{~min}$, alcoholic compounds at $15.55 \mathrm{~min}, 3$, 4-dihydroxybenzyl alcohol polyphenols at $16.56 \mathrm{~min}$ and a small amount of oleic acid at $19.89 \mathrm{~min}$. The results obtained after the hexane extract was analysed, are reported in Figure $2 \mathrm{~b}$. In this case, the main compounds found were palmitic acid and oleic acid, found at $18.30 \mathrm{~min}$ and $19.89 \mathrm{~min}$, respectively.

In this study the liquid-liquid extraction was preferred for its simplicity and convenience (Obied et al., 2005). The extraction with hexane in order to remove the lipidic fraction has been carried out by some authors (Ceccon et al., 2001; De Marco et al., 2007; Lesage-Meessene et al., 2001) whereas others only extracted with ethyl acetate after acidification (Lesage-Meessene et al., 2001). Ethyl acetate was chosen for this study because it is frequently used to extract bio-phenols from aqueous matrices such as OOWW (Lesage-Meessene et al., 2001). There are some studies that indicate the loss of some biophenols (Bullock et al. 1996; Lafkaa et al., 2011; Zafra et al., 2006), but in contrast, ethyl acetate was chosen as the most suitable solvent for hydroxytyrosol (Allouche et al., 2004) because it is selective towards low and medium molecular weight phenols. This solvent is also employed in the food industry, in confectionery, beverages, candy and for artificial fruit essences.

Otherwise, the main compounds in OOWW from the two-phase centrifuge process, identified in the ethyl acetate extract after the method of centrifugation + LLE with ethyl acetate, are shown in Figure 3. Comparing both ethyl acetate extracts shown in Figures $2 \mathrm{a}$ and 3 , it can be noted that these samples were centrifuged but the extraction with hexane did not have any influence. As can be seen by comparing both figures, there was no presence of palmitic acid or any significant differences in the amount of oleic acid, tyrosol and hydroxytyrosol in both chromatograms. This fact is quite relevant, since it pinpoints that the extraction with hexane is useless and it could be eliminated to avoid spending this solvent uselessly.

Figure 4a shows the main compounds in the twophase OOWW centrifuge effluent identified in the ethyl acetate extract resulting from the method consisting of LLE with hexane and ethyl acetate. The comparison of Figure 2a (Ethyl acetate extract with centrifugation) and Figure $4 \mathrm{a}$ (Ethyl acetate extract without centrifugation) reveals that the only difference is a major quantity of oleic acid in the sample without centrifuging, but there are no differences in the quantity of phenolic compounds.

Figure $4 \mathrm{~b}$ shows the results obtained after the analysis of the hexane extract.

Figures $2 \mathrm{~b}$ and $3 \mathrm{~b}$ confirm that hexane only extracts oleic acid and palmitic acid. Comparing Figure $2 b$ (Hexane extract with centrifugation) and Figure $4 b$ (Hexane extract without centrifugation), it is noted that there was a major quantity of oleic acid and palmitic acid in the hexane extract of the sample that was not centrifuged.

On another hand, the main compounds found in the OOWW from two-phase centrifuge identified in the ethyl acetate extract after the method comprising just LLE with ethyl acetate are reported in Figure 5. This method required more time to separate the aqueous phase from the ethyl acetate fraction in the first extraction.

Both samples, extracted only with ethyl acetate and without hexane, shown in Figures 3 and 5, have in common that the phenols were the same but the centrifuged sample contained less oleic acid. 
a)

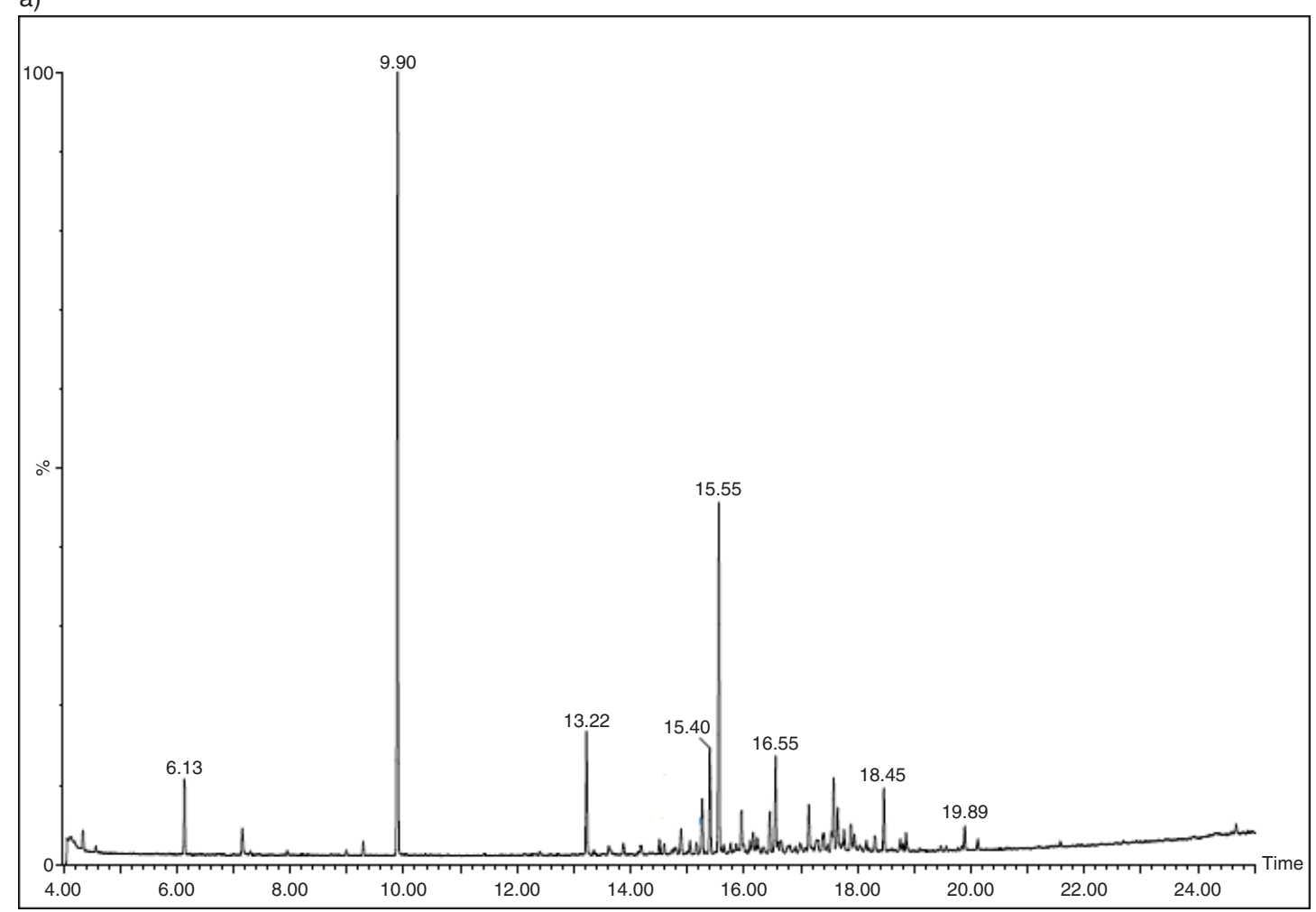

b)

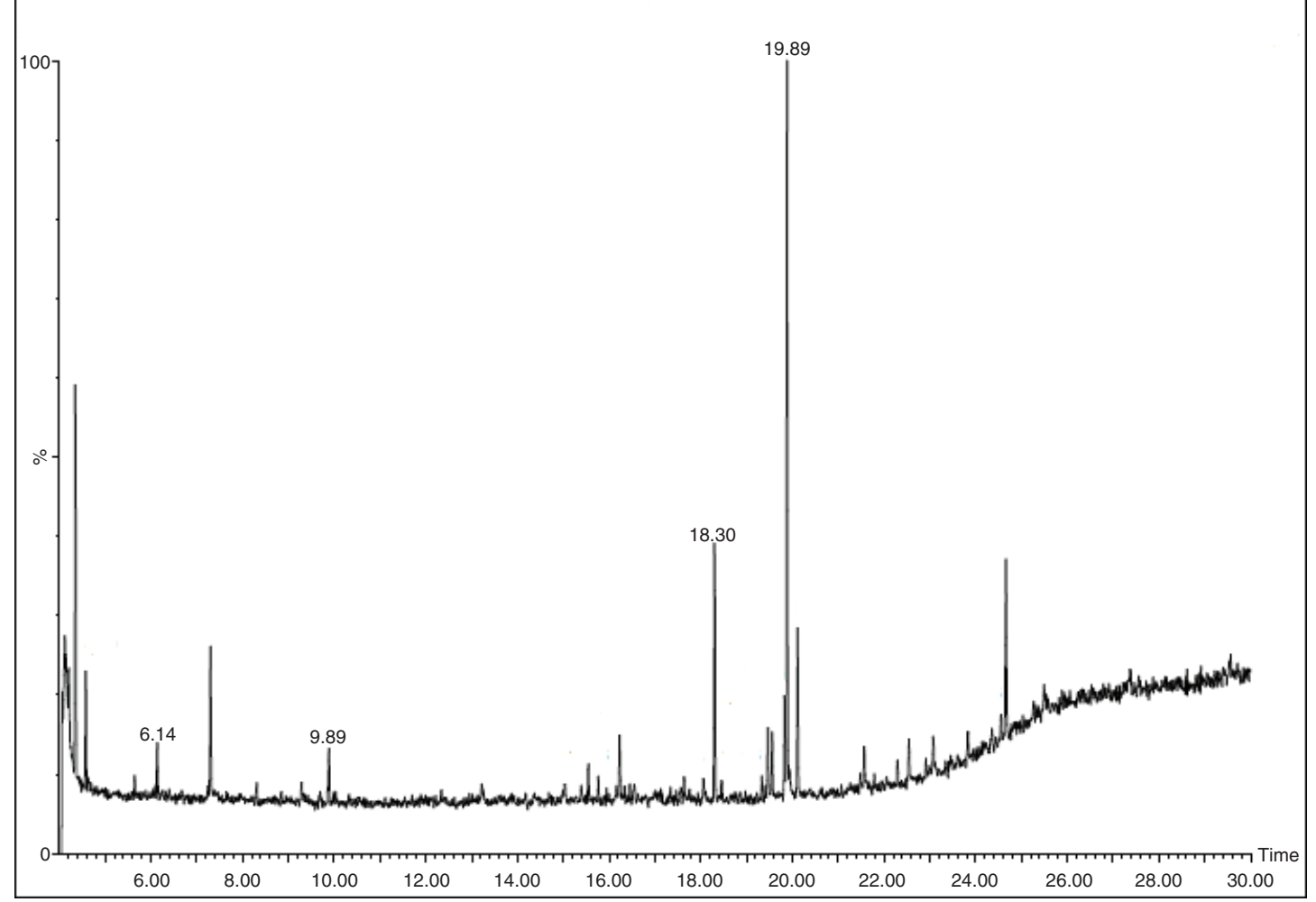

FIGURE 2. GC chromatograms of the compounds of interest in olive oil washing wastewater (OOWW) identified after method 1 in the: a) Ethyl acetate extract. Scan EI+ TIC 1.61e8: 6.13 min: 2-Hydroxypropanoic acid, 9.90: Butanedioic acid (succinic acid), 13.22: Tyrosol, 15.40: Hydroxytyrosol, 15.55: Alcoholic compound, 16.56: 3,4-Dihydroxybenzyl alcohol, 18.46: 3-Hydroxyphenil acetic acid, 19.89: Oleic acid. b) Hexane extract. Method 1. Scan EI+ TIC 6.81e6: 6.14: 2-Hydroxypropanoic acid, 9.89: Butanedioic acid (succinic acid), 18.30: Hexadecanoic acid (palmitic acid), 19.89: Oleic acid. 


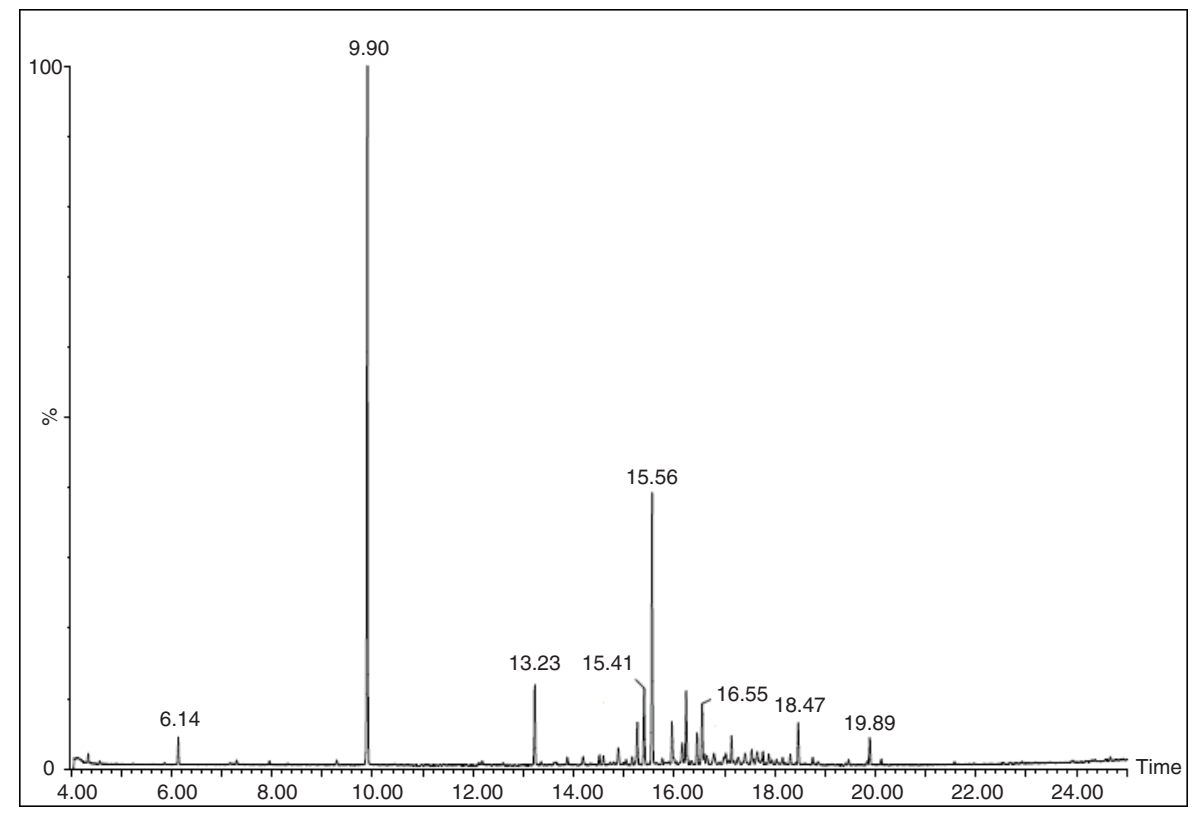

FIGURE 3. GC chromatogram of the compounds of interest in olive oil washing wastewater (OOWW) identified after method 2 in the Ethyl acetate extract. Scan EI+ TIC 3.03e8: 6.14: 2-Hydroxypropanoic acid, 9.90: Butanedioic acid (succinic acid), 13.23: Tyrosol, 15.41: Hydroxytyrosol, 15.56: Alcoholic compound, 16.55: 3,4-Dihydroxybenzyl alcohol, 18.47: 3-Hydroxyphenil acetic acid, 19.89: Oleic acid.

Additionally, Figure 6a shows the main compounds in OOWW identified in the ethyl acetate extract after the centrifugation + SPE method, whereas Figure $6 \mathrm{~b}$ shows the main compounds in OOWW from the centrifuge identified in the ethyl acetate extract after the method of SPE alone.

Comparing the extractions in the solid phase (Figures 6a and 6b), analogous results to those previously observed with the LLE were attained, revealing that in the previously centrifuged sample (Figure 6a) there were no lipids whereas in the notcentrifuged one (Figure 6b) there was oleic acid, oleic acid with a methyl group and palmitic acid, which were retained by the resin.

Finally, the best phenolic extraction method was used for the further extraction and subsequent analysis using olive washing water (OWW). Figure 6c shows the main compounds in OWW identified in the ethyl acetate extract after the method of centrifugation + SPE. In this case, other different phenolic compounds were identified since it is another type of olive mil wastewater.

After the analysis of these OOWW, the compounds extracted by ethyl acetate were 2-hydroxypropanoic acid, butanedioic acid (succinic acid), tyrosol, hydroxytyrosol, alcoholic compounds, 3,4-dihydroxybenzyl alcohol, 3-hydroxyphenil acetic acid and oleic acid. These compounds were the same in all the methods used, with the exception that in methods 5 and 6, 2-hydroxypropanoic acid did not appear since it was not retained by the SPE columns. In method 4 and 6 there was also palmitic acid because in these methods no previous centrifugation or hexane extraction was performed. The compounds found in the hexane extract were palmitic and oleic acids.

The best methods to recover the phenolic compounds were methods 2 and 5 in which a centrifugation was carried out before extraction with ethyl acetate, since the target phenols were barely lost and a cleaner fraction was obtained. Using method 5, another OWW sample was analyzed and the compounds found were cresol, catechol, 4-methylcatechol, hydrocinnamic acid, p-hydroxy-hydrocinnamic acid but only a small quantity of hydroxytyrosol and no tyrosol was found.

Although hydroxytyrosol and tyrosol were described since they are the most commonly referenced components, it is worth highlighting that there are also interesting uses for the other compounds identified, such as hydrocinnamic acid, which is a color stabilizer (Hernández et al. 2006), an antioxidant and radical scavenger (Kikuzaki et al., 2002), an antioxidant together with glutathione (Bouzanquet et al., 2012) and it is a flavor precursor. Succinic acid, which was also identified, is not a phenolic compound but is useful for energy metabolism in plants, and human 
a)

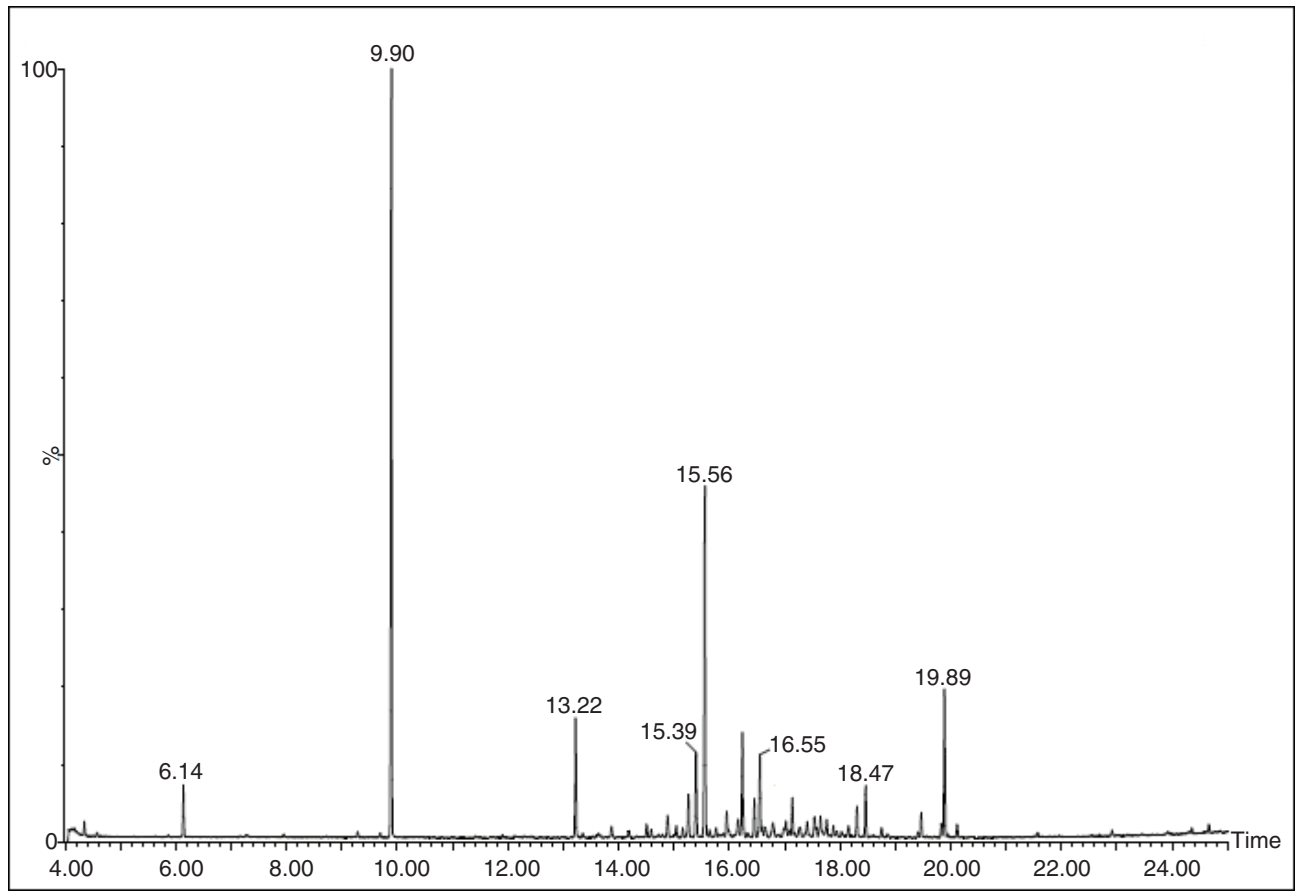

b)

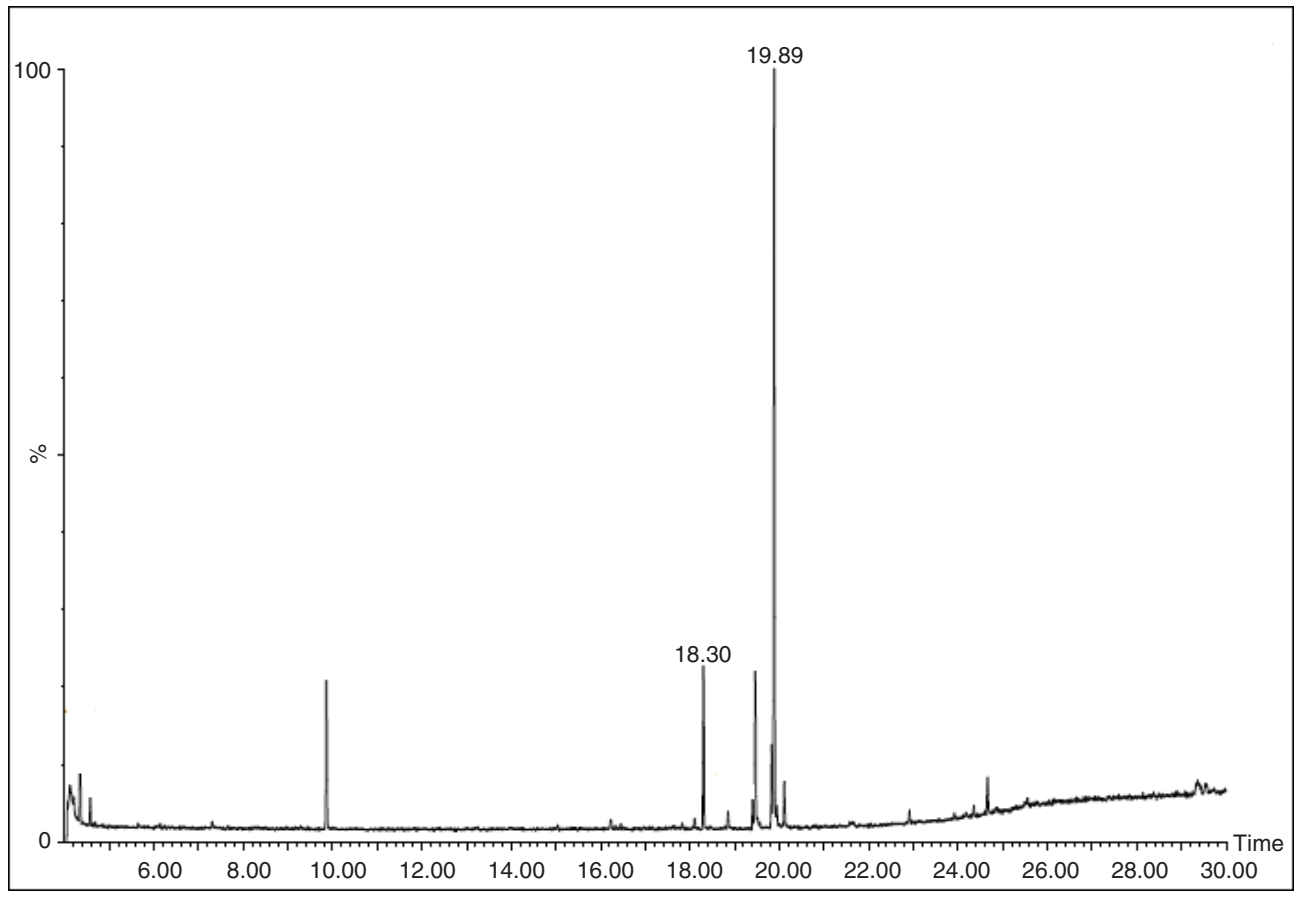

FIGURE 4. GC chromatograms of the compounds of interest in olive oil washing wastewater (OOWW) after method 3 identified in the: a) Ethyl acetate extract. Scan EI+ TIC 2.43e8: 6.14: 2-Hydroxypropanoic acid, 9.90: Butanedioic acid (succinic acid), 13.22: Tyrosol, 15.39: Hydroxytyrosol, 15.56: Alcoholic compound, 16.55: 3,4-Dihydroxybenzyl alcohol, 18.47: 3-Hydroxyphenil acetic acid, 19.89: Oleic acid. b) Hexane extract. Scan EI+ TIC 1.87e 7: 18.30: Hexadecanoic acid (palmitic acid), 19.89: Oleic acid. 


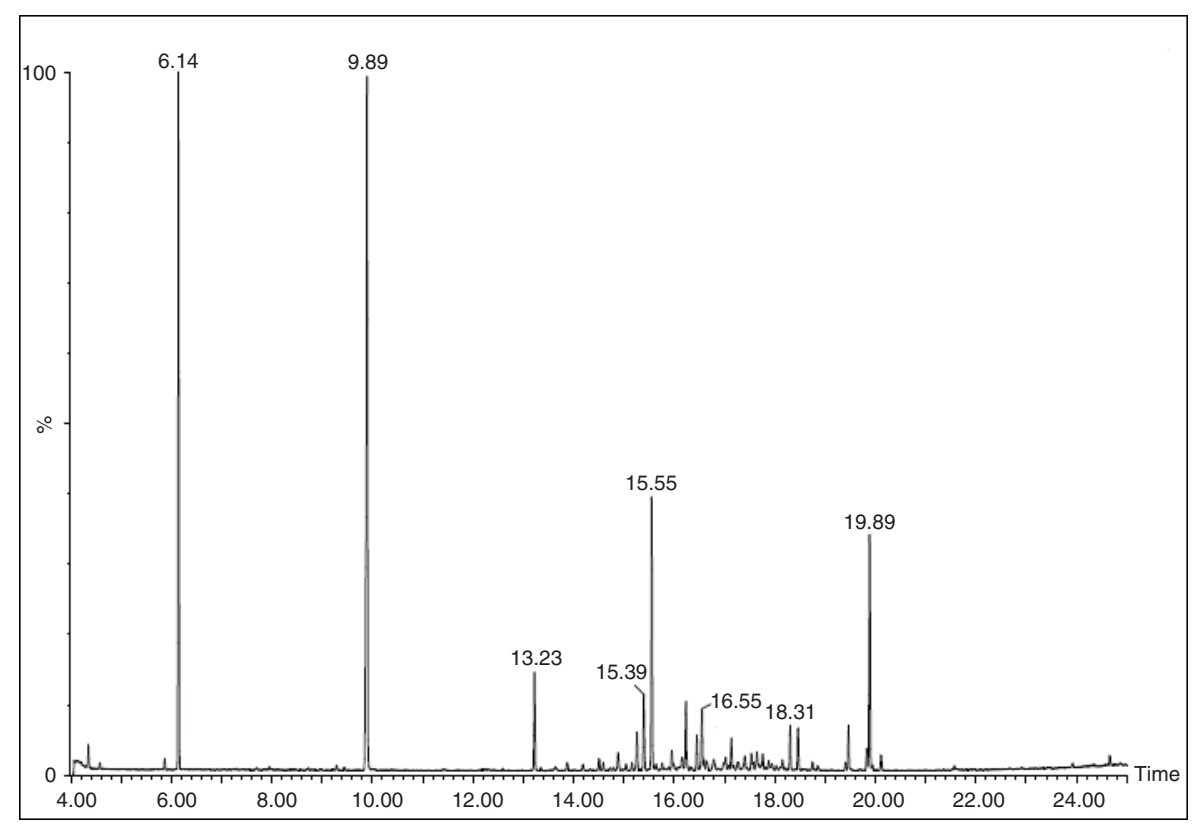

FIGURE 5. GC chromatogram of the compounds of interest in olive oil washing wastewater (OOWW) after method 4 identified in the Ethyl acetate extract. Scan EI+ TIC 1.49e8: 6.14: 2-Hydroxypropanoic acid, 9.89: Butanedioic acid (succinic acid), 13.22: Tyrosol, 15.39: Hydroxytyrosol, 15.55: Alcoholic compound, 16.55: 3,4-Dihydroxybenzyl alcohol, 18.31: Hexadecanoic acid (palmitic acid), 19.89: Oleic acid.

and animal tissue. A major application is its use in biodegradable plastics and in automotive engineering, nonwovens and fibers, as well as sportswear, furniture and even the construction industry (Succinity, 2016).

In other studies, OMW consisting of a mixture of oil washing waste water, olive washing wastewater and other residues generated in the oil industry were analyzed. This mixture, along with the fact that the chemical composition of OMW depends on the variety of the olives, the stage of maturity, storage time and climate, among other factors (Obied et al., 2005), could explain the identification of different phenolic compounds in other studies.

To sum up, the most important compounds found in OOWW were tyrosol, hydroxytyrosol and succinic acid, whereas the most interesting compounds found in OWW were cresol, catechol, 4-methylcatechol, hydrocinnamic acid, p-hydroxy-hydrocinnamic acid. The recovery of these bio-phenolic fractions in olive mill wastewater will help valorize these effluents, and at the same time minimize a deleterious environmental problem in producing countries.

\section{CONCLUSIONS}

The goal of this work was to identify the polyphenols present in the wastewater generated from two-phase olive oil production, specifically from the washing of the olives, OOWW, and from the vertical centrifugation, OWW, since it possesses antioxidant properties which are beneficial for health and industrial applications, whereas these effluents represent a serious environmental problem because these compounds are phytotoxic and difficult to degrade.

Before reaching this goal, it is crucial to establish a good method of extraction. After the identification of bio-phenols present in OOWW through simple methods such as liquid-liquid extraction using ethyl acetate, it was concluded that for recovering the phenolic fraction, a previous centrifugation of the sample is more effective than extraction with hexane to eliminate the remaining lipid fraction (palmitic and oleic acids) in the OOWW. With this centrifugation, only lipids are removed but not phenolic compounds. Method 2 is the most appropriate for this: centrifugation and extraction with ethyl acetate, or if a solid phase extraction is preferred, good results are also obtained with a previous centrifugation as described in method 5.

The most important compounds found in OOWW were tyrosol, hydroxytyrosol and succinic acid.

On the other hand, the most interesting compounds found in OWW were determined to be cresol, catechol, 4-methylcatechol, hydrocinnamic acid, p-hydroxy-hydrocinnamic acid. 

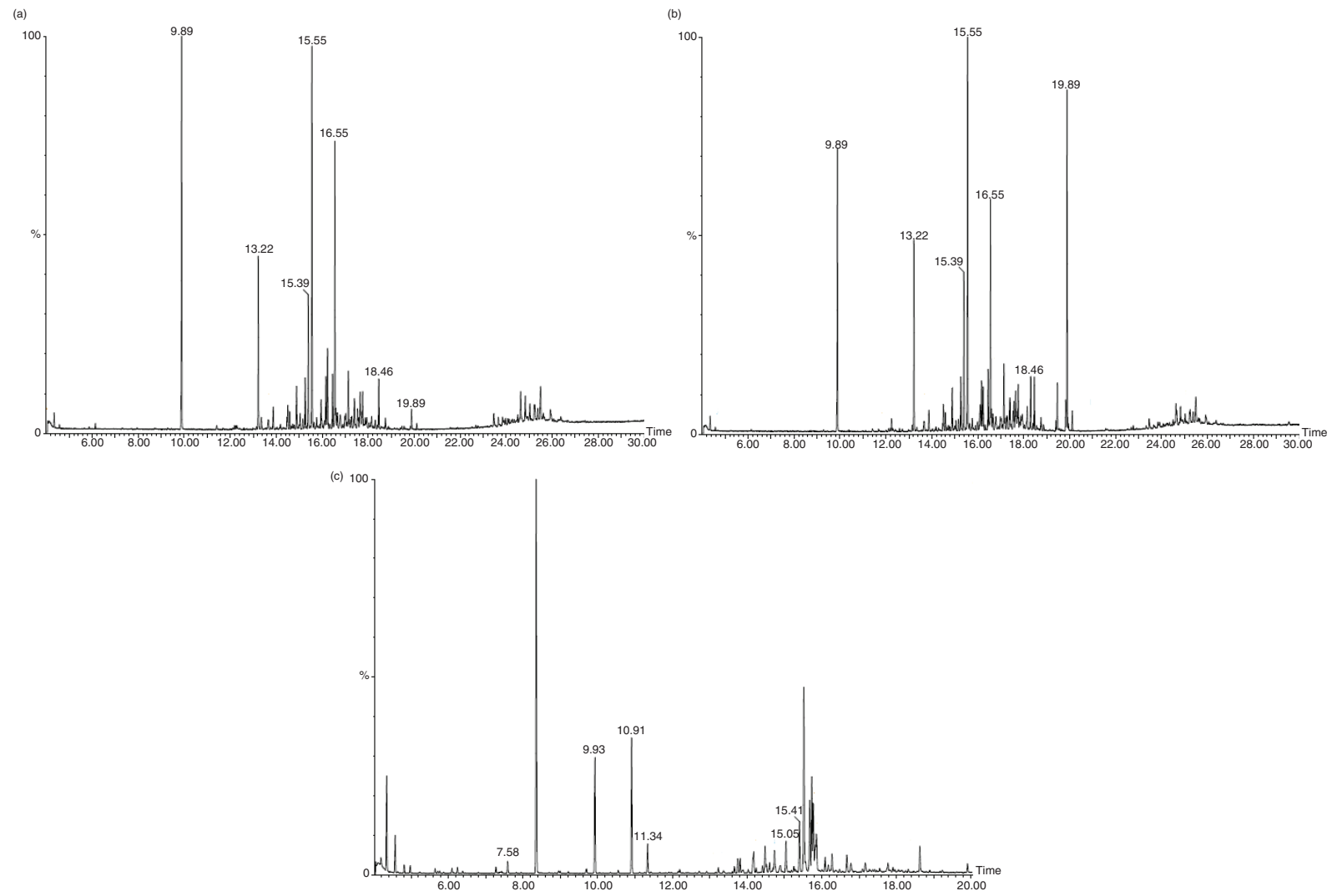

FIGURE 6. GC chromatograms of the compounds of interest in a) olive oil washing wastewater (OOWW) after method 5 identified in the Ethyl acetate extract. Scan EI+ TIC 7.68e7: 9.89: Butanedioic acid (succinic acid), 13.22: Tyrosol, 15.39: Hydroxytyrosol, 15.55: Alcoholic compound, 16.55: 3,4-Dihydroxybenzyl alcohol, 18.46: 3-Hydroxyphenil acetic acid, 19.89: Oleic acid. b) olive oil washing wastewater (OOWW) after method 6 identified in the Ethyl acetate extract. Scan EI+ TIC 8.03e7: 9.89: Butanedioic acid (succinic acid), 13.22: Tyrosol, 15.39: Hydroxytyrosol, 15.55: Alcoholic compound, 16.55: 3,4-Dihydroxybenzyl alcohol, 18.31: Hexadecanoic acid (palmitic acid), 3-Hydroxyphenil acetic acid, 19.89: Oleic acid. c) wastewater from the washing of the olives (OWW) identified after method 5 in the Ethyl acetate extract. Scan EI+ TIC 1e8: 7.58 min: Cresol, 9.93: Catechol, 10.91: 4-Methylcatechol, 11.34: Hydrocinnamic acid, 15.05: p-Hydroxy-hydrocinnamic acid, 15.41: Hydroxytyrosol.

Once these compounds have been identified on a laboratory scale using easy and cheap methods, other processes such as membrane filtration or resins must be applied for the recovery of polyphenols on an industrial scale.

\section{ACKNOWLEDGEMENTS}

The Spanish Ministry of Science and Innovation is acknowledged for funding the project CTQ201021411: Depuration of wastewater from olive oil industry for its reuse in the process and CTM2014-61105-JIN.

\section{REFERENCES}

Allouche N, Fri I, Sayadi S. 2004. Toward a high yield recovery of antioxidants and purified hydroxytyrosol from olive mill wastewaters. J. Agric. Food Chem. 52, 267-273. http:// dx.doi.org/10.1021/jf034944u

Bisignano G, Tomaino A, Lo Cascio R, Crisafi G, Uccella N, Saija A. 1999. On the in-vitro antimicrobial activity of oleuropein and hydroxytyrosol. J. Pharm. Pharmacol. 51, 971-974. http://dx.doi.org/10.1211/0022357991773258

Borja R, Raposo F, Rincón B. 2006. Treatment technologies of liquid and solid wastes from two-phase olive oil mills. Grasas Aceites 57, 32-46. http://dx.doi.org/10.3989/ gya.2006.v57.i1.20

Bouallagui Z, Han J, Isoda H, Sayadi S. 2011. Hydroxytyrosol rich extract from olive leaves modulates cell cycle progression in MCF-7 human breast cancer cells. Food Chem. Toxicol. 49, 179-184. http://dx.doi.org/10.1016/j.fct.2010.10.014

Bouzanquet Q, Barril C, Clark AC, Dias DA, Scollary GR. 2012. A novel glutathione-hydroxycinnamic acid product generated in oxidative wine conditions. J. Agric. Food Chem. 60, 12186-12195. http://dx.doi.org/10.1021/jf3034072

Brune M, Hallberg L, Skanberg A. 1991. Determination of ironbinding phenolic groups in foods. J. Food Sci. 56, 128-131. http://dx.doi.org/10.1111/j.1365-2621.1991.tb07992.x

Bullock CM, Bicho PA, Zhang Y, Saddler JN. 1996. A solid chemical oxygen demand (COD) method for determining biomass in waste waters. Water Res. 30, 1280-1284. https:// doi.org/10.1016/0043-1354(95)00271-5

Bulotta S, Corradino R, Celano M, D’Agostino M, Maiuolo J, Oliverio M. 2011. Antiproliferative and antioxidant effects on breast cancer cells of oleuropein and its semisynthetic peracetylated derivatives. Food Chem. 127, 1609-1614. http://dx.doi.org/10.1016/j.foodchem.2011.02.025 
Cañizares P, Paz R, Sáez C, Rodrigo MA. 2009. Costs of the electrochemical oxidation of wastewaters: a comparison with ozonation and Fenton oxidation processes. Environ. Manag. 90, 410-420. http://dx.doi.org/10.1016/j. jenvman.2007.10.010

De Marco E, Savarese M, Paduano A, Sacchi R. 2007. Characterization and fractionation of phenolic compounds extracted from olive oil mill wastewaters. Food Chem. 104, 858-867. http://dx.doi.org/10.1016/j.foodchem.2006.10.005

Elkacmi R, Kamil N, Bennajah M, Kitane S. 2016. Extraction of oleic acid from Moroccan olive mill wastewater, Biomed. Res. Int. 2016, 1-9. http://dx.doi.org/10.1155/2016/1397852

Elkacmi R, Kamil N, Bennajah M. 2017. Separation and purification of high purity products from three different olive mill wastewater samples. J. Environ. Chem. Eng. 5, 829-837. http://dx.doi.org/doi:10.1016/j.jece.2017.01.005

Fabiani R, Rosignoli P, De Bartolomeo A, Fuccelli R, Servili M, Morozzi G. 2011. The production of hydrogen peroxide is not a common mechanism by which olive oil phenol compounds induce apoptosis on HL60 cells. Food Chem. 125, 1249-1255. http://dx.doi.org/10.1016/j. foodchem.2010.10.052

Geelings A, López-Huertas E, Morales JC, Boza J, Jiménez J. 2003. Natural products and derivatives thereof for protection against neurodegenerative diseases. Patent no. WO 2003/082259.

Gómez-Acebo E, Alcami J, Aunon D. 2011. Topical use of hydroxytyrosol and derivatives for the prevention of HIV infection'. U.S. Patent Application No. 13/513,061.

Hernández T, Estrella I, Carlavilla D, Martín-Álvarez PJ, Moreno-Arribas MV. 2006. Phenolic compounds in red wine subjected to industrial malolactic fermentation and ageing on lees. Anal. Chim. Acta 563, 116-125. http:// dx.doi.org/10.1016/j.aca.2005.10.061

Hodaifa G, Ochando-Pulido JM, Rodriguez-Vives S, Martinez A. 2013. Optimization of continuous reactor at pilot scale for olive-oil mill wastewater treatment by Fentonlike process. Chem. Eng. J. 220, 117-124. http://dx.doi. org/10.1016/j.cej.2013.01.065

International Olive Oil Council (IOOC) [(accessed on 1 December 2016)]. Available online: http://www.internationaloliveoil.org/

Jiménez S, Micó MM, Arnaldos M, Ferrero E, Malfeito JJ, Medina F, Contreras S. 2017. Integrated processes for produced water polishing: Enhanced flotation/sedimentation combined with advanced oxidation processes. Chemosphere 168, 309-317. http://dx.doi.org/10.1016/j. chemosphere.2016.10.055

Kikuzaki H, Hisamoto M, Hirose K, Akiyama K, Taniguchi H. 2002. Antioxidant properties of ferulic acid and its related compounds. J. Agric. Food Chem. 50, 2161-2168. http:// dx.doi.org/10.1021/jf011348w
Lafkaa TI, Lazoub AE, Sinanoglou VJ, Lazos ES. 2011. Phenolic and antioxidant potential of olive oil mill wastes. Food Chem. 125, 92-98. http://dx.doi.org/10.1016/j. foodchem.2010.08.041

La Scalia G, Micale R, Marra FP, Cannizzaro L. 2017. A sustainable phenolic compound extraction system from olive oil mill wastewater, J. Clean Prod. 142, 3782-3788. http:// dx.doi.org/10.1016/j.jclepro.2016.10.086

Lesage-Meessen L, Navarro D, Maunier S, Sigoillot JC, Lorquin J, Delattre M, Simon JL, Asther M, Labat M. 2001. Simple phenolic content in olive oil residues as a function of extraction systems. Food Chem. 75, 501-507. http://dx.doi. org/10.1016/S0308-8146(01)00227-8

Obied HK, Allen MS, Bedgood DR, Prenzler PD, Robards K, Stockmann R. 2005. Bioactivity and analysis of biophenols recovered from olive mill waste. J. Agric. Food Chem. 53, 823-837. http://dx.doi.org/10.1021/jf048569x

Schieber A, Stintzing FC, Carle R. 2011. By-products of plant food processing as a source of functional compoundsrecent developments. Trends Ecol. Evol. 12, 401-413. http:// dx.doi.org/10.1016/S0924-2244(02)00012-2

Succinity. [(accessed on 5 December 2016)]. Available online: http://www.succinity.com

Takaç S, Karakaya A. 2009. Recovery of Phenolic Antioxidants from Olive Mill Wastewater. Recent Pat. Chem. Eng. 2, 230-237. https://doi.org/10.2174/2211334710902030230

Torrecilla JS. 2010. Phenolic Compounds in Olive Oil Mill Wastewater. Olives and Olive Oil Health and Disease Prevention, chapter 40, Elsevier, pp. 357-365. https://doi. org/10.1016/B978-0-12-374420-3.00040-1

Torres de Pinedo A, Peñalver P, Rondón P, Morales JC. 2005. Efficient lipase-catalyzed of new lipid antioxidants based on a catechol structure. Tetrahedron 61, 7654-7660. http:// dx.doi.org/10.1016/j.tet.2005.05.100

Vázquez-Velasco M, Esperanza L, Lucas R, Gómez-Martínez S, Bastida S, Marcos A. 2011. Effects of hydroxytyrosolenriched sunflower oil consumption on CVD risk factors. Br. J. Nutr. 105, 1448-1452. http://dx.doi.org/10.1017/ S0007114510005015

Visioli F, Poli A, Galli C. 2002. Antioxidant and other biological activities of phenols from olives and olive oil. Med. Res. Rev. 22, 65-75. http://dx.doi.org/10.1002/med.1028

Zafra A, Juárez MJB, Blanca R, Navalón A, González J, Vílchez JL. 2006. Determination of polyphenolic compounds in wastewater olive oil by gas chromatography-mass spectrometry. Talanta 70, 213-218. http://dx.doi.org/10.1016/j. talanta.2005.12.038

Zagklis DP, Vavouraki AI, Kornaros ME, Paraskeva CA. 2015. Purification of olive mill wastewater phenols through membrane filtration and resin adsorption/desorption. $J$. Hazard. Mater. 285, 69-76. http://dx.doi.org/10.1016/j. jhazmat.2014.11.038 